\title{
Alkaloids from Tetrastigma hemsleyanum and Their Anti-Inflammatory Effects on LPS-Induced RAW264.7 Cells
}

Cai Yi Wang ${ }^{1,+}$, Hyun-Jae Jang ${ }^{2,+}{ }^{(1)}$, Yoo Kyong Han ${ }^{1}$, Xiang Dong $\mathrm{Su}^{1}$, Seung Woong Lee ${ }^{2}{ }^{(\mathbb{D})}$, Mun-Chual Rho ${ }^{2}$, Heng-Shan Wang ${ }^{3}$, Seo Young Yang ${ }^{1, *}$ and Young Ho Kim ${ }^{1, *}$

1 College of Pharmacy, Chungnam National University, Daejeon 34134, Korea; wangcaiyiamy@163.com (C.Y.W.); kkoo_@naver.com (Y.K.H.); suxiangdongnicky@163.com (X.D.S.)

2 Immunoregulatory Material Research Center, Korea Research Institute of Bioscience and Biotechnology, 181 Ipsin-gil, Jeongeup-si, Jeonbuk 56212, Korea; water815@kribb.re.kr (H.-J.J.);

lswdoc@kribb.re.kr (S.W.L.); rho-m@kribb.re.kr (M.-C.R.)

3 State Key Laboratory for Chemistry and Molecular Engineering of Medicinal Resources, School of Chemistry and Pharmaceutical Sciences, Guangxi Normal University, Guilin 541004, China; whengshan@163.com

* Correspondence: syyang@cnu.ac.kr (S.Y.Y.); yhk@cnu.ac.kr (Y.H.K.); Tel.: +82-42-821-7321 (S.Y.Y.); +82-42-821-5933 (Y.H.K.)

+ These authors contributed equally.

Academic Editor: Helen D. Skaltsa

Received: 7 April 2018; Accepted: 9 June 2018; Published: 14 June 2018

\begin{abstract}
Alkaloids 1-10 were isolated from the aerial parts of Tetrastigma hemsleyanum (APTH) and obtained from species of the genus Tetrastigma for the first time. The chemical structures of the isolated compounds were identified by NMR, UV, and MS analyses. Their anti-inflammatory activities were investigated by measuring nitric oxide (NO) production in lipopolysaccharide (LPS)-induced RAW264.7 macrophages. Among all the isolates, compounds 6, 7 and 10 showed potent inhibitory activity against LPS-stimulated NO production in RAW264.7 cells $\left(\mathrm{IC}_{50}: 31.9,25.2\right.$ and $6.3 \mu \mathrm{M}$, respectively). Furthermore, APTH and $S-(-)$-trolline (10) inhibited induction of inflammatory cytokines or mediators such as interleukin-1 $\beta$ (IL-1 $\beta$ ) and inducible nitric oxide synthase (iNOS) via suppression of nuclear factor $\mathrm{KB}(\mathrm{NF}-\mathrm{kB})$ translocation into the nucleus. In addition, 10 suppressed extracellular signal-regulated protein kinase 1/2 (ERK1/2) mitogen-activated protein kinase (MAPK) phosphorylation in a dose-dependent manner. These results conclusively demonstrated that compound 10 displays anti-inflammatory activity via suppression of NF- $\mathrm{KB}$ activation and the ERK-MAPK signaling pathway in LPS-stimulated RAW264.7 cells.
\end{abstract}

Keywords: Tetrastigma hemsleyanum; alkaloid; NO production; anti-inflammatory activity

\section{Introduction}

Tetrastigma hemsleyanum Diels et. Gilg, belonging to the grape family Vitaceae, is an herbaceous perennial species native to China [1]. T. hemsleyanum, known as "Sanyeqing", is a well-known edible plant distributed widely in China that is commonly used in folk medicine for treatment of high fever, infantile febrile convulsion, pneumonia, snake bite, and jaundice [2]. Pharmacological studies of T. hemsleyanum have examined its anticancer [3], liver protective, antioxidant [4], anti-inflammatory, analgesic and antipyretic activities [5]. In addition, several studies have investigated the chemical components and biological activities of T. hemsleyanum leaves and roots [6]. Previous studies have indicated that the phenolic constituents of the root of $T$. hemsleyanum inhibit the viability of human 
cancer cells [3] and that the ethyl acetate fraction (EAF) is the major contributor to the various biological activities of the plant [7]. Although T. hemsleyanum has long been used as a traditional Chinese medicine, little is known about its chemical composition [4,8].

Inflammation is a protective response of tissues to harmful stimuli, including injury and invading microbes. This response is a mechanism of the innate immune system to eliminate external pathogens and repair damaged tissue by activating immune cells, blood vessels, and molecular mediators [9]. Acute or chronic inflammation under pathophysiological conditions can cause various inflammatory diseases such as cancer, septic shock, diabetes, atherosclerosis, arthritis, and inflammatory bowel disease [10]. Macrophages play a pivotal role in the inflammation process by producing proinflammatory mediators such as tumor necrosis factor alpha (TNF- $\alpha)$, interleukin $1 \beta$ (IL-1 $\beta$ ), interleukin 6 (IL-6), and nitric oxide (NO) in addition to serving as the host defense mechanism [11,12]. Among the inflammation-related products, NO generally modulates vascular tone to control neuronal and immune functions under normal physiological conditions. However, excessive NO production leads to serious inflammatory disorders due to DNA damage, apoptosis, and reactive oxygen species (ROS) accumulation [13-15]. Large amounts of NO are mainly produced by inducible nitric oxide synthase (iNOS), which is regulated by gene transcription factors such as nuclear factor $\mathrm{kB}$ $(\mathrm{NF}-\kappa \mathrm{B})$ and activator protein 1 (AP-1) [16]. Inhibitors of $\kappa \mathrm{B}(\mathrm{I} \kappa \mathrm{B})$, which binds to inactivated NF- $\kappa \mathrm{B}$ complexes and mitogen-activated protein kinases (MAPKs), are phosphorylated by other upstream signal transduction molecules such as I $\mathrm{B}$ kinase (IKK) and MAPK kinases (MEKs), and the NF- $\kappa$ B and AP-1 transcription factors are activated in the nucleus during inflammation processes [17]. Therefore, targeting of the signaling molecules responsible for inflammation-mediated diseases is important for the development of anti-inflammation agents [18].

In the course of our ongoing search for novel anti-inflammatory agents from important medicinal plants found in the Karst Mountains in southwest China [15], the methanol extract of the aerial parts of T. hemsleyanum (APTH) was shown to exhibit a considerable inhibitory effect on LPS-stimulated NO production in RAW264.7 macrophages $\left(\mathrm{IC}_{50}: 22.69 \pm 0.75 \mu \mathrm{M}\right)$. In addition, we carried out a phytochemical study of APTH. Separation of the EtOAc-soluble fraction of the methanolic extract of APTH resulted in the isolation of ten alkaloids, namely, seven indole alkaloids (1-7), an amide (8), a maleimide (9), and a carboline (10). By comparing the spectral data of these compounds with those in the literature, the alkaloids were identified as indole (1) [19], indole-3-carboxylic acid (2) [20], indole-3-propanoic acid (3) [21], 5-hydroxy-indole-3-carboxaldehyde (4) [22], 5-hydroxy-indole-3-carboxylic acid (5) [22], 6-hydroxy-3,4-dihydro-1-oxo- $\beta$-carboline (6) [23], hippophamide (7) [24], 4-hydroxycinnamide (8) [25], pyrrole-3-propanoic acid (9) [26] and S-(-)-trolline (10) [27], which were isolated from the genus Tetrastigma for the first time (Figure 1, see Supplementary Materials). In the present paper, the isolation and structural elucidation of the alkaloids and their anti-inflammatory activities are described.

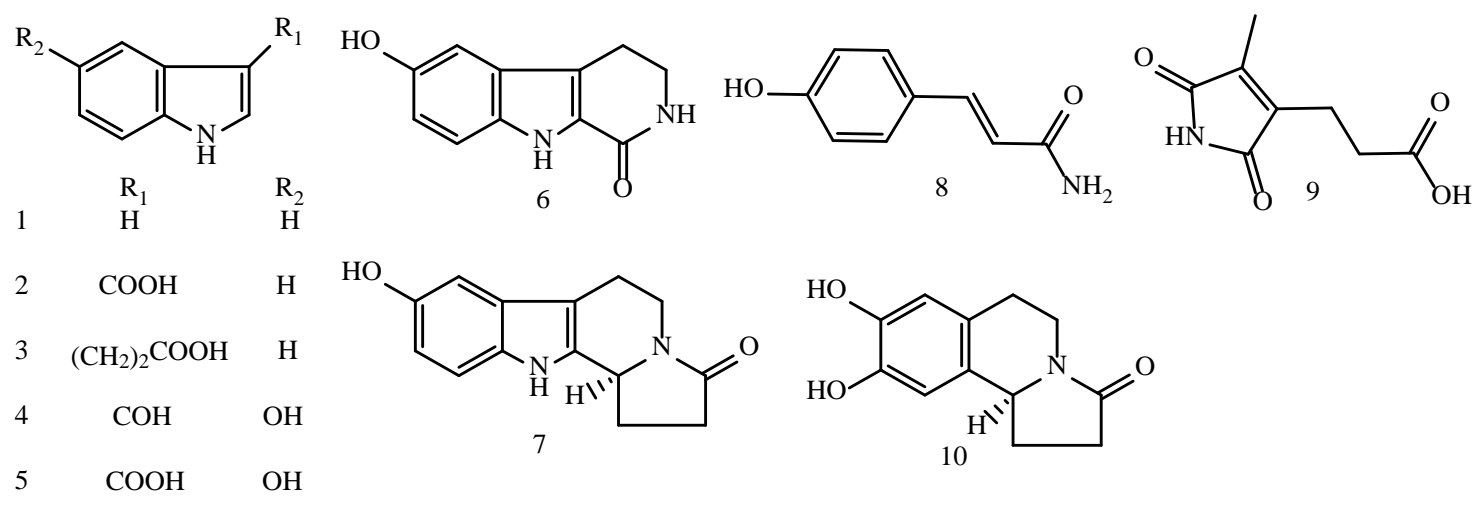

Figure 1. Chemical structures of the alkaloids (1-10) isolated from T. hemsleyanum. 


\section{Results and Discussion}

The anti-inflammatory activities of alkaloids 1-10 were investigated in terms of their ability to inhibit NO production in LPS-treated RAW264.7 macrophages (Table 1). Compounds 6, 7 and 10 showed potent inhibitory activities, with $\mathrm{IC}_{50}$ values of $31.92 \pm 0.01,25.16 \pm 0.41$ and $6.28 \pm 0.45 \mu \mathrm{M}$, respectively, and did not show cytotoxicity at the inhibitory concentration (data not shown).

Table 1. Inhibition of NO production in RAW264.7 macrophages by alkaloids $\mathbf{1}-\mathbf{1 0}{ }^{\mathrm{a}}$.

\begin{tabular}{cccc}
\hline Compounds & IC $_{\mathbf{5 0}}(\boldsymbol{\mu M})$ & Compounds & IC $_{\mathbf{5 0}}(\boldsymbol{\mu M})$ \\
\hline $\mathbf{1}$ & $>50$ & $\mathbf{6}$ & $31.92 \pm 0.01^{*}$ \\
$\mathbf{2}$ & $>50$ & 7 & $25.16 \pm 0.41^{*}$ \\
$\mathbf{3}$ & $>50$ & $\mathbf{8}$ & $>50$ \\
$\mathbf{4}$ & $>50$ & $\mathbf{9}$ & $>50$ \\
$\mathbf{5}$ & $>50$ & $\mathbf{1 0}$ & $6.28 \pm 0.45^{*}$ \\
& & Dexamethasone $^{\mathrm{b}}$ & $0.009 \pm 0.001^{*}$ \\
\hline
\end{tabular}

\footnotetext{
a The inhibitory activities are presented as the concentration $(\mu \mathrm{M})$ giving $50 \%$ inhibition (IC 50$)$ relative to the vehicle control, and the results are the mean of three replications. ${ }^{b}$ Positive control. The data are presented as the mean $\pm \operatorname{SEM}(n=3)$ of three independent experiments. ${ }^{*} p<0.05$ vs. the LPS-treated control group.
}

Structure-activity relationship (SAR) studies of these alkaloids have shown that the lactam moiety rather than the indole group in compounds 6, 7, and 10 may be an important structural element for their anti-inflammatory activity. Moreover, five-membered lactam rings, such as those in compounds 7 and 10, enhance the inhibitory effects more than six-membered lactam rings, such as that in compound 6. Therefore, the hexahydroindolizinone pharmacophore in compound $\mathbf{1 0}$ may play an important role in its anti-inflammatory activity.

Excessive production of proinflammatory cytokines, such as TNF- $\alpha$, IL-1 $\beta$ and IL-6, induces systemic inflammation, which can result in severe inflammatory symptoms such as acute respiratory distress syndrome (ARDS) and multiple organ dysfunction syndrome (MODS) [28]. Therefore, regulation of inflammatory cytokine levels is essential for improving the progression of acute inflammatory syndrome. To further examine the anti-inflammation activities of APTH and compound 10, their effects on LPS-stimulated production of prostaglandin $E_{2}$ (PGE 2 ), IL-1 $\beta$ and IL-6 mediators were evaluated using ELISAs. As shown in Figure 2, APTH and compound 10 both reduced LPS-induced PGE $_{2}$ and IL-1 $\beta$ production in a dose-dependent manner but did not affect IL-6 levels (Figure 2). $\mathrm{PGE}_{2}$ derived from arachidonic acid contributes to the development of various inflammatory diseases accompanied by fever, edema, and pain [29,30]. Nonsteroidal anti-inflammatory drugs (NSAIDs) are well known to exert anti-inflammatory activity through inhibition of PGHS-derived prostaglandin synthesis [31]. Therefore, the results suggest that APTH and compound 10 exhibit potent anti-inflammatory activity via inhibition of proinflammatory mediators and cytokines, such as $\mathrm{NO}, \mathrm{PGE}_{2}$, and IL-1 $\beta$.

We performed Western blot analyses to investigate the effects of APTH and compound 10 on iNOS and COX-2 protein expression. As shown Figure 3, both APTH and compound 10 significantly inhibited iNOS and COX-2 protein expression (Figure 3). These results indicate that APTH and compound 10 suppress the proinflammatory mediators $\mathrm{NO}$ and $\mathrm{PGE}_{2}$ through inhibition of iNOS and COX-2 protein expression and that suppression of iNOS and COX-2 expression is correlated with inhibition of NO and $\mathrm{PGE}_{2}$ production. In the inflammation response, $\mathrm{NO}$ and $\mathrm{PGE}_{2}$ are synthesized by iNOS and COX-2, respectively [32]. Thus, abundant iNOS and COX-2 expression promotes proinflammatory signaling pathways [33], and suppression of the expression of these inflammatory enzymes might be a therapeutic approach for the treatment of inflammation-related diseases [34]. 
(A)

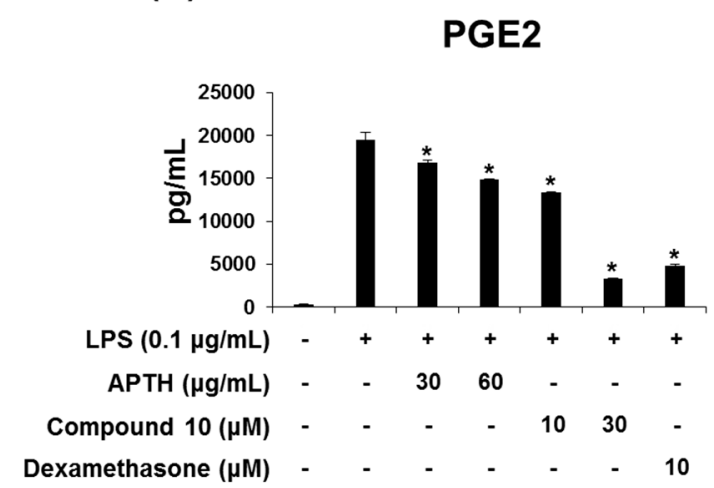

(C)

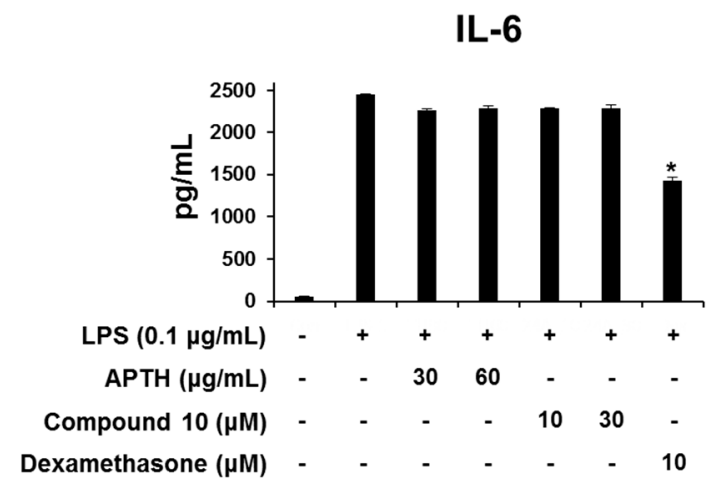

(B)

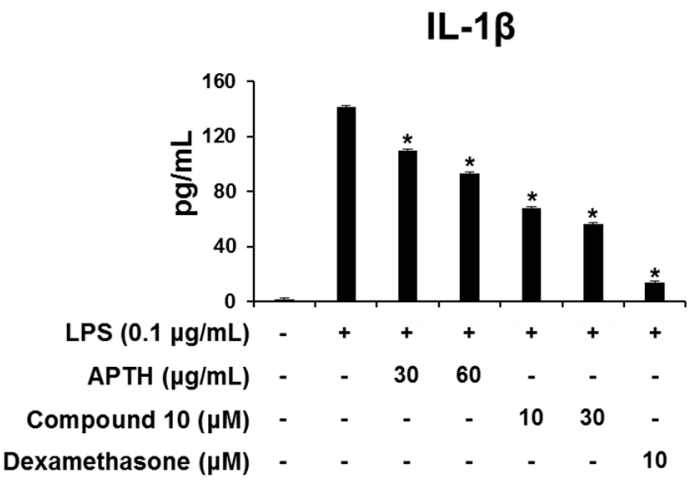

Figure 2. Effects of APTH and compound 10 on LPS-stimulated PGE 2 , IL-1 $\beta$ and IL-6 production in RAW264.7 macrophages. Cells were preincubated for $1 \mathrm{~h}$ with or without the test compounds and then stimulated for $16 \mathrm{~h}$ with LPS $(0.1 \mu \mathrm{g} / \mathrm{mL})$. The PGE 2 (A), IL-1 $\beta$ (B), and IL-6 (C) levels were measured by ELISA. The results are expressed as the means \pm standard error of the mean (SEM). Dexamethasone was used as the positive control. Values of ${ }^{*} p<0.05$ are based on a comparison with the LPS-treated control group.

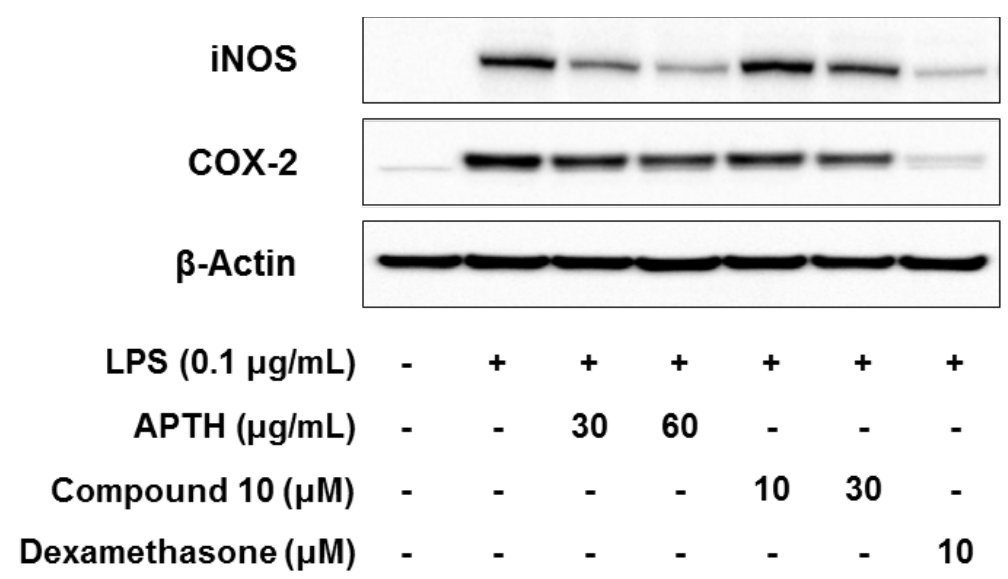

Figure 3. Effects of APTH and compound 10 on iNOS and COX-2 expression in LPS-induced RAW264.7 cells. Cells were pretreated for $1 \mathrm{~h}$ in the presence or absence of samples and then treated for $16 \mathrm{~h}$ with LPS $(0.1 \mu \mathrm{g} / \mathrm{mL})$. The iNOS and COX-2 protein expression levels were detected by Western blot analysis, and $\beta$-actin was used as the loading control. Dexamethasone served as the positive control. 
The expression of inflammatory cytokines or mediators, such as NO, PGE 2 , IL-1 $\beta$, IL-6, iNOS, and COX-2, is mainly regulated by activation of the NF- $\mathrm{B}$ transcription factor, which plays a key role in advancing the inflammatory process [35]. Inactive complexes bound to NF- $\mathrm{B}$, the p65/p50 heterodimer, and $I_{\kappa} B$ in the cytosol are degraded by phosphorylation of $I_{\kappa} B(p-I \kappa B)$, which leads to NF- $\kappa B$ translocation to the nucleus and transcription of proinflammatory mediators [36]. To investigate whether APTH and compound $\mathbf{1 0}$ affect NF- $\mathrm{BB}$ activation, Western blotting was performed to analyze p-IкB and p65 levels in cytosolic and nuclear extracts, respectively. As shown Figure 4, APTH and compound 10 suppressed p-IкB and translocation of p65 to a considerable degree (Figure 4). These data suggest that APTH and compound $\mathbf{1 0}$ decreased the NF- $\mathrm{B}$ activity induced by LPS through inhibition of $\mathrm{p}-\mathrm{I} \kappa \mathrm{B}$ in the cytosol. Therefore, the anti-inflammatory activity of APTH and compound 10 may be attributed to regulation of NF- $\mathrm{KB}$ signaling cascades.

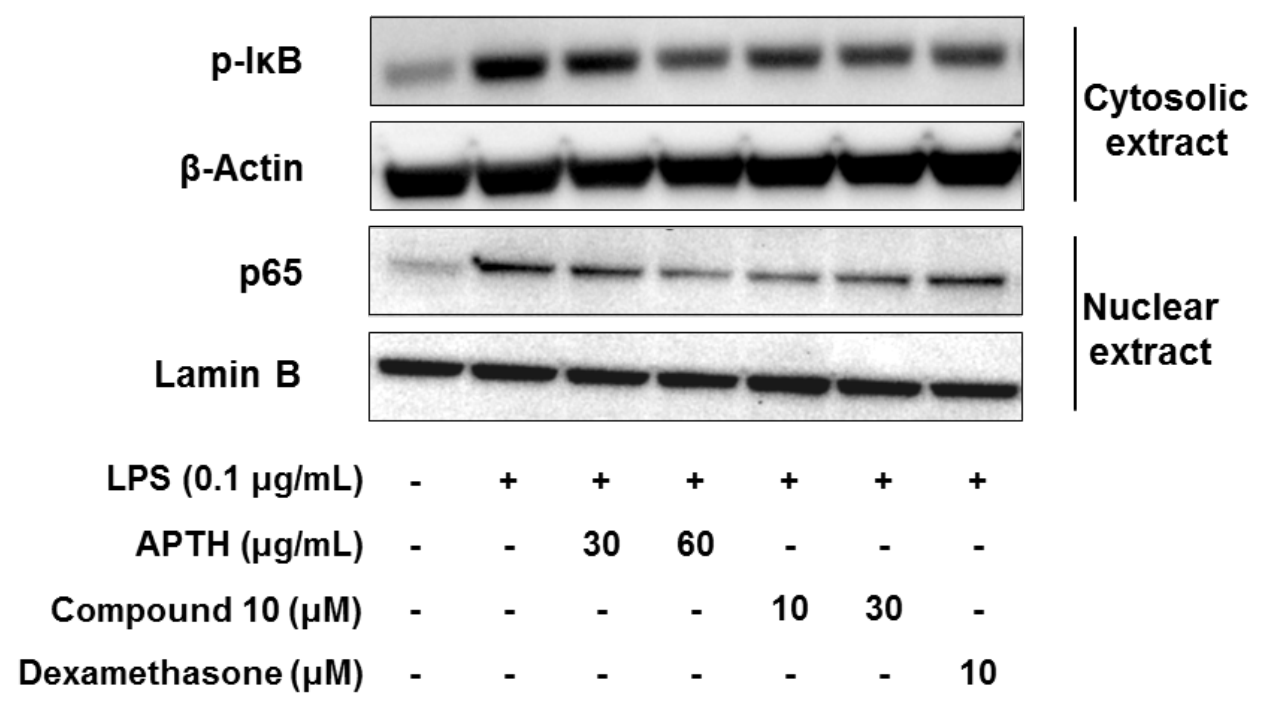

Figure 4. Effects of APTH and compound 10 on NF-kB signaling pathways in LPS-treated RAW264.7 macrophages. Cells were pretreated for $1 \mathrm{~h}$ in the presence or absence of samples and then stimulated for $1.5 \mathrm{~h}$ with LPS $(0.1 \mu \mathrm{g} / \mathrm{mL})$. Cell cytosolic and nuclear extracts were prepared to determine whether I $\mathrm{B}$ phosphorylation levels and p65 translocation to the nucleus. $\beta$-Actin and Lamin B were used as loading controls. Dexamethasone served as the positive control.

MAPK is also a key mediator in promoting the inflammatory response [37]. c-Jun N-terminal kinase (JNK), extracellular signal-regulated kinase (ERK), and p38 are representative components of the MAPK signaling cascades, and their phosphorylation results in activation of proinflammatory transcription factors, such as AP-1 and cAMP response element-binding protein (CREB) [10]. Therefore, the inhibitory effects of APTH and compound 10 on LPS-stimulated MAPK activation were assessed by analyzing the phosphorylation levels of JNK, ERK, and p38 (p-JNK, p-ERK, and p-p38) using Western blotting. As shown Figure 5, APTH dose-dependently inhibited LPS-stimulated p-JNK, p-ERK, and p-p38; however, compound 10 only suppressed p-ERK (Figure 5). These findings suggest that the three major functions of MAPKs were substantially reduced by APTH, and compound 10 is involved in suppression of ERK-MAPK activation.

Similarly, a previous study demonstrated that flavonoids obtained from the roots of T. hemsleyanum regulate the LPS-induced inflammatory response in RAW264.7 cells via the NF- $\mathrm{B}$ and JNK-MAPK signaling pathways [37]. However, the present study found that APTH can also be considered an effective anti-inflammatory agent, similar to the root extract of T. hemsleyanum.

Dexamethasone is a steroidal anti-inflammatory agent for treatment of inflammatory and autoimmune diseases, such as asthma, osteoarthritis, and inflammatory bowel disease [38-42]. Recent studies have reported drug delivery strategies to improve agent effectiveness in regulating immune 
responses in macrophages and microfold (M) cells [40-42]. Among many delivery strategies, such as nanoparticles, liposomal drug carriers, and microparticle-based drug delivery, poly(DL-lactic acid) microspheres containing dexamethasone demonstrated significantly higher efficacy than treatment with dexamethasone alone [42]. Therefore, employment of a drug delivery system targeting immune-related cells may be useful for improving the efficacy of small-molecule natural products such as compound $\mathbf{1 0 .}$

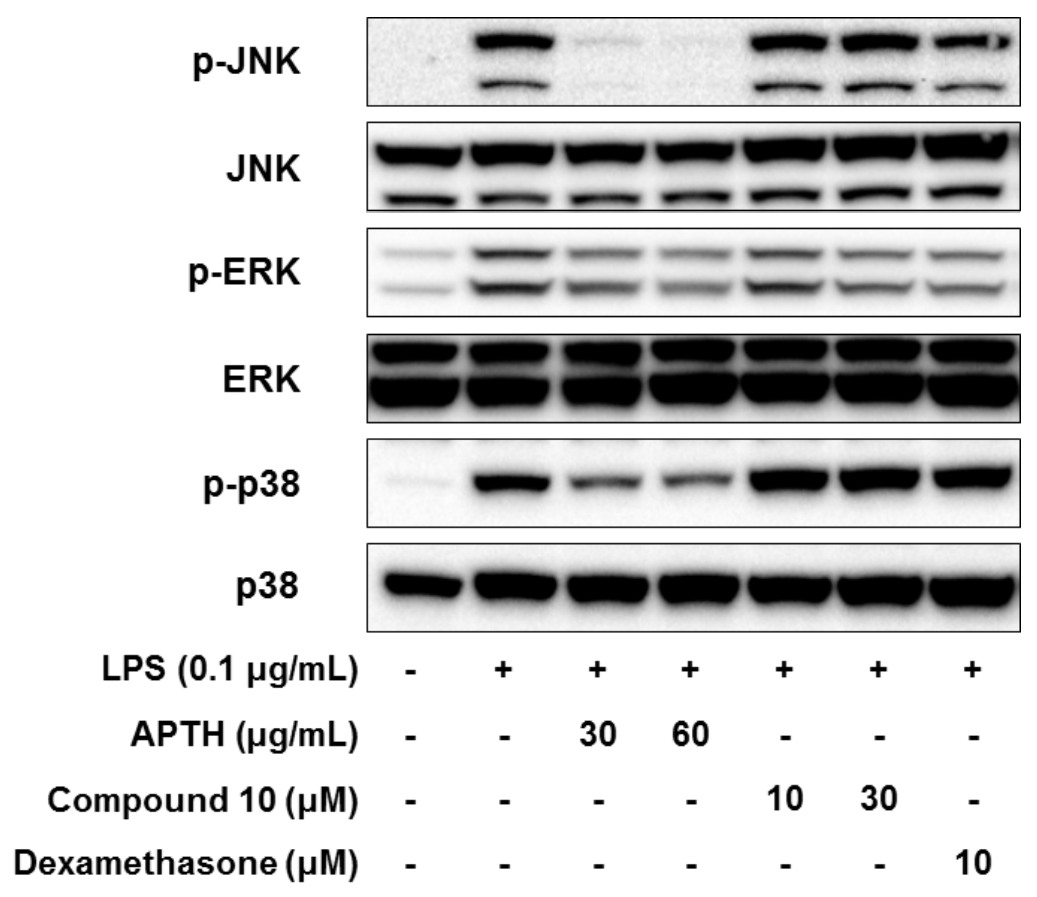

Figure 5. Effects of APTH and compound 10 on JNK, ERK, and p38 MAPK phosphorylation in LPS-stimulated RAW264.7 cells. Cells were pretreated for $1 \mathrm{~h}$ in the presence or absence of samples and then treated for $0.5 \mathrm{~h}$ with LPS $(0.1 \mu \mathrm{g} / \mathrm{mL})$. The phosphorylation of the JNK, ERK, and p38 proteins was measured by Western blotting, and total JNK, ERK, and p38 protein levels were used as loading controls. Dexamethasone served as the positive control.

\section{Materials and Methods}

\subsection{General Information}

Optical rotations were determined on a JASCO P-2000 polarimeter (Hachioji, Tokyo, Japan). CD spectra were recorded with a Chirascan spectropolarimeter (Applied Photophysics, Leatherhead, UK). High-resolution electrospray ionization mass spectrometry (ESI-MS) analysis was conducted on an Agilent 6530 Accurate-Mass Q-TOF LC/MS system (Agilent Technologies, Palo Alto, CA, USA). NMR spectra were recorded on Bruker AM600 FT-NMR and Bruker BioSpin 400 NMR spectrometers (Rheinstetten, Germany). Column chromatography (CC) was performed on silica gel (Kiesel gel 60, 70-230 mesh and 230-400 mesh, Merck, Darmstadt, Germany), YMC*GEL (ODS-A, 12 nm S-150 $\mu \mathrm{m}$, YMC, Kyoto, Japan) and Sephadex LH-20 (Sigma-Aldrich, St. Louis, MO, USA) resins. Precoated silica gel $60 \mathrm{~F}_{254}$ (1.05554.0001, Merck, Darmstadt, Germany) and RP-18 F 254 S plates (1.15685.0001, Merck) were used for TLC. Preparative high-performance liquid chromatography (HPLC) separations were carried out using a Shimadzu LC-6AD (Shimadzu, Kyoto, Japan) instrument with a YMC-Pack ODS-A column (20 mm I.D. $\times 250 \mathrm{~mm}, \mathrm{~S}-5 \mu \mathrm{m})$ and an SPD-20A wavelength detector set at $210 \mathrm{~nm}$. 


\subsection{Plant Material}

The aerial parts of T. hemsleyanum were collected from Linchuan County, Guilin City, Guangxi Zhuang Autonomous Region in July 2016. The plant was identified by Professor Shao-Qing Tang (Guangxi Normal University), and a voucher specimen (No. 20160110) was deposited at the School of Life Sciences, Guangxi Normal University.

\subsection{Extraction and Isolation}

The dried stems and leaves of T. hemsleyanum $(25.0 \mathrm{~kg})$ were extracted with $90 \%$ ethanol three times $\left(75^{\circ} \mathrm{C}, 3 \mathrm{~h}\right.$ each time). All the filtrates were concentrated to afford $1 \mathrm{~kg}$ of crude extract. The crude extract was suspended in water and then sequentially partitioned into $n$-hexane, ethyl acetate and $n$-butanol (three times each). The EAF was subjected to silica gel CC with a $\mathrm{CH}_{2} \mathrm{Cl}_{2}-\mathrm{MeOH}$ gradient with increasing polarity (30:1, 20:1, 15:1, 10:1, 8:1, 7:1, 6:1, 5:1, 3:1, 1:1, and 0:1), yielding four fractions (frs. 1-4). Fr. 1 was separated by silica gel CC (EtOAc-Hex, 1:2) and provided three fractions (frs. 1-1 to 1-3). Fr. 1-1 was purified by LH-20 CC (MeOH) and then subjected to HPLC $\left(\mathrm{MeOH}-\mathrm{H}_{2} \mathrm{O}\right)$ to yield compound $10(4.4 \mathrm{mg})$. Fr. 1-2 was subjected to $\mathrm{LH}-20 \mathrm{CC}(\mathrm{MeOH})$ to give compound $2(1.1 \mathrm{mg})$. Fr. 1-3 was also purified by LH-20 CC (MeOH) and then subjected to HPLC $\left(\mathrm{MeOH}-\mathrm{H}_{2} \mathrm{O}\right)$ to give compound $6(10.6 \mathrm{mg})$. Fr. 2 was subjected to RP- $18 \mathrm{CC}(30 \%, 50 \%, 70 \%$, and $100 \% \mathrm{MeOH})$ and then to LH-20 CC (MeOH) and HPLC (MeOH- $\left.\mathrm{H}_{2} \mathrm{O}\right)$ to afford compound $3(9.0 \mathrm{mg})$. Fr. 3 was purified on an RP-18 column $(30 \%, 50 \%, 70 \%$, and $100 \% \mathrm{MeOH})$, followed by subsequent purification via LH-20 CC ( $\mathrm{MeOH})$ and $\mathrm{HPLC}\left(\mathrm{CH}_{3} \mathrm{CN}, 0.1 \%\right.$ TFA in $\left.\mathrm{H}_{2} \mathrm{O}\right)$, affording compound $\mathbf{1}(4.5 \mathrm{mg})$. Fr. 4 was loaded onto a silica gel column by VLC and successively eluted with $\mathrm{CH}_{2} \mathrm{Cl}_{2}: \mathrm{MeOH}: \mathrm{H}_{2} \mathrm{O}$ (8:1:0.125 and 8:2:0.25) to yield Fr. 4-1. Fr. 4-1 was subjected to $\mathrm{LH}-20 \mathrm{CC}(\mathrm{MeOH})$ to obtain four sub-fractions (frs. 4-1-1 to 4-1-4). Fr. 4-1-1 was fractionated by HPLC $\left(\mathrm{CH}_{3} \mathrm{CN}, 0.1 \%\right.$ TFA in $\left.\mathrm{H}_{2} \mathrm{O}\right)$ to afford compound 7 (12.4 mg). Fr. 4-1-2 was separated by HPLC $\left(\mathrm{CH}_{3} \mathrm{CN}, 0.1 \%\right.$ TFA in $\left.\mathrm{H}_{2} \mathrm{O}\right)$ to yield 8 (7.0 mg). Fr. 4-1-3 was also separated by HPLC $\left(\mathrm{CH}_{3} \mathrm{CN}, 0.1 \%\right.$ TFA in $\left.\mathrm{H}_{2} \mathrm{O}\right)$ and provided compounds $4(6.6 \mathrm{mg})$ and $5(5.4 \mathrm{mg})$. Fr. 4-1-4 was purified by HPLC $\left(\mathrm{CH}_{3} \mathrm{CN}, 0.1 \%\right.$ TFA in $\left.\mathrm{H}_{2} \mathrm{O}\right)$ to give compound $9(6.2 \mathrm{mg})$.

\subsection{Measurement of NO, PGE,$I L-1 \beta$ and IL-6 Production and Cell Cytotoxicity}

RAW264.7 cells (TIB-71, ATCC, Manassas, VA, USA) were obtained from American Type Culture Collection (ATCC). NO production was measured using a previously described method [43,44]. Briefly, RAW264.7 macrophages were seeded into 96-well plates at a density of $5 \times 10^{5}$ cells/well, and after being incubated with samples for $1 \mathrm{~h}$, the cells were treated with LPS $(0.1 \mu \mathrm{g} / \mathrm{mL})$ for $24 \mathrm{~h}$. Equal volumes of the cell culture supernatant and Griess reagent were mixed, and the absorbance of the mixtures was recorded at $550 \mathrm{~nm}$. The levels of PGE 2 , IL-1 $\beta$ and IL-6 cytokines were measured with ELISAs. RAW264.7 cells $\left(2 \times 10^{6}\right.$ cells/well) were cultured in a 6-well plate for $24 \mathrm{~h}$. The cells were activated by LPS $(0.1 \mu \mathrm{g} / \mathrm{mL})$ for $16 \mathrm{~h}$ after being pretreated with samples for $1 \mathrm{~h}$, and the concentrations of $\mathrm{PGE}_{2}, \mathrm{IL}-1 \beta$ and IL- 6 in the supernatants were measured using an ELISA kit (R\&D Systems, Minneapolis, MN, USA). The cell viabilities were quantified with an MTT (3-(4,5-dimethylthiazol-2-yl)-2,5 diphenyl tetrazolium bromide) assay after $24 \mathrm{~h}$ of incubation with the samples [45].

\subsection{Western Blotting Analysis}

Western blot analyses were carried out as described previously [45]. In brief, RAW264.7 cells $\left(2 \times 10^{6}\right.$ cell/well) were pretreated with the methanol extracts of the aerial parts of T. hemsleyanum (APTH) and compound 10 for $1 \mathrm{~h}$, and then cells were stimulated with LPS $(0.1 \mu \mathrm{g} / \mathrm{mL})$ for $0.5,1.5$, and $24 \mathrm{~h}$. The cytosol and nuclear fractions were extracted using an NE-PER Nuclear and Cytoplasmic Extraction Kit (Thermo Fisher Scientific, San Jose, CA, USA) according to the manufacturer's protocol. Each cell lysate was loaded on an $8 \%$ or $10 \%$ sodium dodecyl sulfate (SDS) polyacrylamide gel, and then, the proteins were transferred onto PVDF membranes. After blocking the membrane in $0.01 \%$ 
Tween 20 (TBST) containing 5\% skimmed milk powder for $1 \mathrm{~h}$, the membrane was incubated with the appropriate primary antibody (targeting iNOS, COX-2, $\beta$-actin, p-IкB, p65, Lamin B, p-JNK, JNK, p-ERK1/2, ERK1/2, p-p38, or p38; Cell Signaling Technology, Beverly, MA, USA) at 1:1000 dilution overnight at $4{ }^{\circ} \mathrm{C}$. The membrane was washed in TBST and incubated with the appropriate horseradish peroxide-conjugated secondary antibody at 1:2000 dilution for $30 \mathrm{~min}$. After the membrane was washed in TBST, the immunoreactive bands were visualized using a West-ZOL Plus kit (iNtRON Biotechnology, Seoul, Korea) and detected with a ChemiDoc ${ }^{\mathrm{TM}}$ XRS system (Bio-Rad Laboratories Inc., Hercules, CA, USA).

\subsection{Statistical Analysis}

The data are presented as the means \pm standard error of the mean (SEM). All statistical analyses were performed using Prism 5 software (GraphPad software, San Diego, CA, USA). Student's $t$-test was used to determine significant differences between the control and experimental groups, with $p<0.05$ indicating a significant difference.

\section{Conclusions}

In summary, ten alkaloids were isolated from $\mathrm{APTH}$, and their chemical structures were determined from based on NMR and MS spectroscopic data. APTH and S-(-)-trolline (10) showed potent anti-inflammatory activity in LPS-treated RAW264.7 cells by inhibiting various inflammatory cytokines or mediators, such as NO, PGE 2 , IL-1 $\beta$, iNOS, and COX-2, and these inhibitory activities are closely related to regulation of the NF- $\mathrm{KB}$ signaling pathway. The crude extract APTH attenuated the phosphorylation of three major MAPKs (JNK, ERK, and p38), whereas compound 10 inhibited only the activity of ERK-MAPK. Therefore, $S-(-)$-trolline (10) may be primarily responsible for the anti-inflammatory activity of APTH. These results revealed that APTH and S-(-)-trolline (10) could be used to develop novel therapeutic agents for treatment of inflammatory diseases.

Supplementary Materials: The following are available online. Physical and spectroscopic data of compounds 1-10.

Author Contributions: C.Y.W. performed compound isolation and structure elucidation; H.-J.J. performed the bioassay experiments. Y.K.H. and X.D.S. performed associated experiments; S.W.L. and M.-C.R. provided funding; H.-S.W. collected the plant; S.Y.Y. and Y.H.K. conceived and designed the experiments and provided additional support.

Funding: This study was supported by the Priority Research Center Program through the National Research Foundation of Korea (NRF) funded by the Ministry of Education the Ministry of Science and Technology, Republic of Korea [2009-0093815] and was supported by a grant from the KRIBB Research Initiative Program [KGM2221844].

Conflicts of Interest: The authors declare no conflict of interest.

\section{References}

1. Shao, Q.; Deng, Y.; Fang, H.; Zhao, X. Optimization of polysaccharides extraction from Tetrastigma hemsleyanum diels et gilg using response surface methodology. Int. J. Biol. Macromol. 2011, 49, 958-962. [CrossRef] [PubMed]

2. Xu, C.-J.; Ding, G.-Q.; Fu, J.-Y.; Meng, J.; Zhang, R.-H.; Lou, X.-M. Immunoregulatory effects of ethyl-acetate fraction of extracts from Tetrastigma hemsleyanum diels et. Gilg on immune functions of icr mice. Biomed. Environ. Sci. 2008, 21, 325-331. [CrossRef]

3. Xiong, Y.; Wu, X.; Rao, L. Tetrastigma hemsleyanum (sanyeqing) root tuber extracts induces apoptosis in human cervical carcinoma hela cells. J. Ethnopharmacol. 2015, 165, 46-53. [CrossRef] [PubMed]

4. Sun, Y.; Li, H.; Hu, J.; Li, J.; Fan, Y.-W.; Liu, X.-R.; Deng, Z.-Y. Qualitative and quantitative analysis of phenolics in Tetrastigma hemsleyanum and their antioxidant and antiproliferative activities. J. Agric. Food Chem. 2013, 61, 10507-10515. [CrossRef] [PubMed]

5. Ye, C.L.; Liu, X.G. Extraction of flavonoids from Tetrastigma hemsleyanum diels et gilg and their antioxidant activity. J. Food Process Preserv. 2015, 39, 2197-2205. [CrossRef] 
6. Hossain, M.A.; Shah, M.D.; Gnanaraj, C.; Iqbal, M. In vitro total phenolics, flavonoids contents and antioxidant activity of essential oil, various organic extracts from the leaves of tropical medicinal plant Tetrastigma from Sabah. Asian Pac. J. Trop. Med. 2011, 4, 717-721. [CrossRef]

7. Feng, Z.; Hao, W.; Lin, X.; Fan, D.; Zhou, J. Antitumor activity of total flavonoids from Tetrastigma hemsleyanum diels et gilg is associated with the inhibition of regulatory $t$ cells in mice. OncoTargets Ther. 2014, 7, 947-956.

8. Sun, Y.; Hui, Q.; Chen, R.; Li, H.; Peng, H.; Chen, F.; Deng, Z. Apoptosis in human hepatoma HepG2 cells induced by the phenolics of Tetrastigma hemsleyanum leaves and their antitumor effects in $\mathrm{H} 22$ tumor-bearing mice. J. Funct. Food. 2018, 40, 349-364. [CrossRef]

9. Barton, G.M. A calculated response: Control of inflammation by the innate immune system. J. Clin. Investig. 2008, 118, 413-420. [CrossRef] [PubMed]

10. Yu, T.; Ahn, H.M.; Shen, T.; Yoon, K.; Jang, H.-J.; Lee, Y.J.; Yang, H.M.; Kim, J.H.; Kim, C.; Han, M.H. Anti-inflammatory activity of ethanol extract derived from Phaseolus angularis beans. J. Ethnopharmacol. 2011, 137, 1197-1206. [CrossRef] [PubMed]

11. Yoon, H.J.; Moon, M.E.; Park, H.S.; Im, S.Y.; Kim, Y.H. Chitosan oligosaccharide (COS) inhibits LPS-induced inflammatory effects in RAW 264.7 macrophage cells. Biochem. Biophys. Res. Commun. 2007, 358, 954-959. [CrossRef] [PubMed]

12. Yun, K.-J.; Kim, J.-Y.; Kim, J.-B.; Lee, K.-W.; Jeong, S.-Y.; Park, H.-J.; Jung, H.-J.; Cho, Y.-W.; Yun, K.; Lee, K.-T. Inhibition of LPS-induced no and PGE2 production by asiatic acid via NF-kB inactivation in RAW 264.7 macrophages: Possible involvement of the IKK and MAPK pathways. Int. Immunopharmacol. 2008, 8, 431-441. [CrossRef] [PubMed]

13. Laroux, F.S.; Lefer, D.J.; Kawachi, S.; Scalia, R.; Cockrell, A.S.; Gray, L.; Van der Heyde, H.; Hoffman, J.M.; Grisham, M.B. Role of nitric oxide in the regulation of acute and chronic inflammation. Antioxid. Redox Signal. 2000, 2, 391-396. [CrossRef] [PubMed]

14. Li, C.-Q.; Pang, B.; Kiziltepe, T.; Trudel, L.J.; Engelward, B.P.; Dedon, P.C.; Wogan, G.N. Threshold effects of nitric oxide-induced toxicity and cellular responses in wild-type and p53-null human lymphoblastoid cells. Chem. Res. Toxicol. 2006, 19, 399-406. [CrossRef] [PubMed]

15. Pando, M.P.; Verma, I.M. Signal-dependent and-independent degradation of free and NF- $\kappa B-b o u n d ~ I \kappa B \alpha$. J. Biol. Chem. 2000, 275, 21278-21286. [CrossRef] [PubMed]

16. Suh, S.-J.; Chung, T.-W.; Son, M.-J.; Kim, S.-H.; Moon, T.C.; Son, K.H.; Kim, H.P.; Chang, H.W.; Kim, C.-H. The naturally occurring biflavonoid, ochnaflavone, inhibits LPS-induced iNOS expression, which is mediated by ERK1/2 via NF-kB regulation, in RAW264.7 cells. Arch. Biochem. Biophys. 2006, 447, 136-146. [CrossRef] [PubMed]

17. Lu, Y.; Suh, S.-J.; Kwak, C.-H.; Kwon, K.-M.; Seo, C.-S.; Li, Y.; Jin, Y.; Li, X.; Hwang, S.-L.; Kwon, O. Saucerneol $\mathrm{F}$, a new lignan, inhibits iNOS expression via MAPKs, NF- $\mathrm{KB}$ and AP-1 inactivation in LPS-induced RAW264. 7 cells. Int. Immunopharmacol. 2012, 12, 175-181. [CrossRef] [PubMed]

18. García-Lafuente, A.; Guillamón, E.; Villares, A.; Rostagno, M.A.; Martínez, J.A. Flavonoids as anti-inflammatory agents: Implications in cancer and cardiovascular disease. Inflamm. Res. 2009, 58, 537-552. [CrossRef] [PubMed]

19. Kamieńska-Trela, K.; Kania, L.; Bechcicka, M. ${ }^{13} \mathrm{C}$ NMR studies on the structure of $5 H$ - and $6 H$-indolo-[2,3-b] quinolines and the related compounds. J. Mol. Struct. 2003, 661, 209-218. [CrossRef]

20. Wang, Y.; Hämäläinen, A.; Tois, J.; Franzén, R. Preparation of indole-phosphine oxazoline (indphox) ligands and their application in allylic alkylation. Tetrahedron-Asymmetry 2010, 21, 2376-2384. [CrossRef]

21. Lee, H.-J.; Kim, W.-C.; Jeon, S.-Y.; Kim, J.-W.; Joo, G.-J.; Rhee, I.-K.; Song, K.-S. Growth inhibitors of soybean seedling from Bacillus sp. IJ-31. J. Korean Soc. Appl. Biol. Chem. 2003, 46, 100-104.

22. Sauleau, P.; Martin, M.-T.; Dau, M.-E.T.H.; Youssef, D.T.; Bourguet-Kondracki, M.-L. Hyrtiazepine, an azepino-indole-type alkaloid from the red sea marine sponge Hyrtios erectus. J. Nat. Prod. 2006, 69, 1676-1679. [CrossRef] [PubMed]

23. Lee, S.Y.; Kim, K.H.; Lee, I.K.; Lee, K.H.; Choi, S.U.; Lee, K.R. A new flavonol glycoside from Hylomecon vernalis. Arch. Pharm. Res. 2012, 35, 415-421. [PubMed]

24. OuYang, J.; Zhou, W.N.; Li, G.; Wang, X.Y.; Ding, C.X.; Suo, Y.R.; Wang, H.L. Three new alkaloids from Hippophae rhamnoides Linn. subsp. sinensis Rousi. Helv. Chim. Acta 2015, 98, 1287-1291. [CrossRef] 
25. Lueoend, R.M.; Walker, J.; Neier, R.W. Assessment of the active-site requirements of 5-aminolevulinic acid dehydratase: Evaluation of substrate and product analogs as competitive inhibitors. J. Org. Chem. 1992, 57, 5005-5013. [CrossRef]

26. Kawai, N.; Matsuda, M.; Uenishi, J. Stereoselective synthesis of tetrahydroisoquinoline alkaloids: (-)-trolline, (+)-crispin A, (+)-oleracein E. Tetrahedron 2011, 67, 8648-8653. [CrossRef]

27. Oda, S.; Hirasawa, H.; Shiga, H.; Nakanishi, K.; Matsuda, K.-I.; Nakamua, M. Sequential measurement of IL-6 blood levels in patients with systemic inflammatory response syndrome (sirs)/sepsis. Cytokine 2005, 29, 169-175. [CrossRef] [PubMed]

28. Oh, Y.-C.; Jeong, Y.H.; Cho, W.-K.; Hwang, Y.-H.; Ma, J.Y. Inhibitory effects of dianthi herba ethanolic extract on inflammatory and nociceptive responses in murine macrophages and mouse models of abdominal writhing and ear edema. J. Ethnopharmacol. 2018, 211, 375-383. [CrossRef] [PubMed]

29. Portanova, J.P.; Zhang, Y.; Anderson, G.D.; Hauser, S.D.; Masferrer, J.L.; Seibert, K.; Gregory, S.A.; Isakson, P.C. Selective neutralization of prostaglandin E2 blocks inflammation, hyperalgesia, and interleukin 6 production in vivo. J. Exp. Med. 1996, 184, 883-891. [CrossRef] [PubMed]

30. Guay, J.; Bateman, K.; Gordon, R.; Mancini, J.; Riendeau, D. Carrageenan-induced paw edema in rat elicits a predominant prostaglandin E2 (PGE2) response in the central nervous system associated with the induction of microsomal PGE2 synthase-1. J. Biol. Chem. 2004, 279, 24866-24872. [CrossRef] [PubMed]

31. Funk, C.D. Prostaglandins and leukotrienes: Advances in eicosanoid biology. Science 2001, 274, 1871-1875. [CrossRef] [PubMed]

32. Tursun, X.; Zhao, Y.; Talat, Z.; Xin, X. Anti-inflammatory effect of Rosa rugosa flower extract in lipopolysaccharide-stimulated RAW264. 7 macrophages. Biomol. Ther. 2016, 24, 184-190. [CrossRef] [PubMed]

33. Kundu, J.K.; Surh, Y.J. Inflammation: Gearing the journey to cancer. Mutat. Res. 2008, 659, 15-30. [PubMed]

34. Redington, A.E.; Meng, Q.H.; Springall, D.R.; Evans, T.J.; Créminon, C.; Maclouf, J.; Holgate, S.T.; Howarth, P.H.; Polak, J.M. Increased expression of inducible nitric oxide synthase and cyclo-oxygenase-2 in the airway epithelium of asthmatic subjects and regulation by corticosteroid treatment. Thorax 2001, 56, 351-357. [PubMed]

35. Garg, A.D.; Kaczmarek, A.; Krysko, O.; Vandenabeele, P.; Krysko, D.V.; Agostinis, P. ER stress-induced inflammation: Does it aid or impede disease progression? Trends Mol. Med. 2012, 18, 589-598. [CrossRef] [PubMed]

36. Li, D.; Chen, J.; Ye, J.; Zhai, X.; Song, J.; Jiang, C.; Wang, J.; Zhang, H.; Jia, X.; Zhu, F. Anti-inflammatory effect of the six compounds isolated from Nauclea officinalis pierrc ex pitard, and molecular mechanism of strictosamide via suppressing the NF-KB and MAPK signaling pathway in LPS-induced RAW264.7 macrophages. J. Ethnopharmacol. 2017, 196, 66-74. [PubMed]

37. Liu, D.; Cao, G.; Han, L.; Ye, Y.; SiMa, Y.; Ge, W. Flavonoids from Radix Tetrastigmae inhibit TLR4/MD-2 mediated JNK and NF-кB pathway with anti-inflammatory properties. Cytokine 2016, 84, 29-36. [CrossRef] [PubMed]

38. Léguillette, R.; Tohver, T.; Bond, S.L.; Nicol, J.A.; McDonald, K.J. Effect of Dexamethasone and Fluticasone on Airway Hyperresponsiveness in Horses With Inflammatory Airway Disease. J. Vet. Intern. Med. 2017, 31, 1193-1201. [PubMed]

39. Huebner, K.D.; Shrive, N.G.; Frank, C.B. Dexamethasone inhibits inflammation and cartilage damage in a new model of post-traumatic osteoarthritis. J. Orthop. Res. 2014, 32, 566-572. [CrossRef] [PubMed]

40. Davoudi, Z.; Peroutka-Bigus, N.; Bellaire, B.; Wannemuehler, M.; Barrett, T.A.; Narasimhan, B.; Wang, Q. Intestinal organoids containing poly(lactic-co-glycolic acid) nanoparticles for the treatment of inflammatory bowel diseases. J. Biomed. Mater. Res. A 2018, 106, 876-886. [PubMed]

41. Nguyen, T.X.; Huang, L.; Gauthier, M.; Yang, G.; Wang, Q. Recent advances in liposome surface modification for oral drug delivery. Nanomedicine 2016, 11, 1169-1185. [CrossRef] [PubMed]

42. Nakase, H.; Okazaki, K.; Tabata, Y.; Uose, S.; Ohana, M.; Uchida, K.; Matsushima, Y.; Kawanami, C.; Oshima, C.; Ikada, Y.; et al. Development of an oral drug delivery system targeting immune-regulating cells in experimental inflammatory bowel disease: A new therapeutic strategy. J. Pharmacol. Exp. Ther. 2000, 292, 15-21. [PubMed] 
43. Jang, H.-J.; Lee, S.; Lee, S.-J.; Lim, H.-J.; Jung, K.; Kim, Y.H.; Lee, S.W.; Rho, M.-C. Anti-inflammatory activity of eudesmane-type sesquiterpenoids from Salvia plebeia. J. Nat. Prod. 2017, 80, 2666-2676. [CrossRef] [PubMed]

44. Jang, H.-J.; Lee, S.-J.; Kim, C.Y.; Lee, S.; Jung, K.; Hwang, J.T.; Choi, J.H.; Park, J.H.; Lee, S.W.; Rho, M.-C. Effect of sunlight radiation on the growth and chemical constituents of Salvia plebeia R. Br. Molecules 2017, 22, 1279. [CrossRef] [PubMed]

45. Jang, H.-J.; Lee, S.-J.; Lee, S.; Jung, K.; Lee, S.W.; Rho, M.-C. Acyclic Triterpenoids from Alpinia katsumadai inhibit IL-6-induced STAT3 activation. Molecules 2017, 22, 1611. [CrossRef] [PubMed]

Sample Availability: Samples of the compounds are available from the authors.

(C) 2018 by the authors. Licensee MDPI, Basel, Switzerland. This article is an open access article distributed under the terms and conditions of the Creative Commons Attribution (CC BY) license (http:// creativecommons.org/licenses/by/4.0/). 